\title{
EKSISTENSI MAKAM BADANG SEBAGAI WISATA RELIGI DI PULAU BURU TANJUNG BALAI KARIMUN
}

\section{EXISTENCE OF BADANG TOMB AS A RELIGI TOUR ON THE BURU ISLAND TANJUNG BALAI KARIMUN}

\author{
Dewi Saptiani $^{1)}$, Arnesih ${ }^{2)}$ \\ ${ }^{1}$ Program Studi Pendidikan sejarah, FKIP, UNRIKA, Batam \\ 1) e-mail: dewi.saptiani2105@gmail.co.id \\ 2) arnesih1303@gmail.com
}

\begin{abstract}
Abstrak
Penelitian ini melihat eksistensi makam Badang sebagai Wisata Religi di Pulau Buru Tanjung Balai Karimun. Masyarakat Pulau Buru percaya terhadap makam Badang sebagai tempat mengabulkan permintaan. Tujuan penelitian ini untuk mendeskripsikan keberadaan makam Badang sebagai wisata religi. Jenis penelitian ini adalah kualitatif dengan metode deskriptif. Penelitian ini dilakukan di Pulau Buru, sumber data dalam penelitian ini ada dua yaitu sumber primer seperti tokoh masyarakat, staff kecamatan, data kecamatan dan sumber sekunder seperti pengunjung, hasil pustaka. Teknik pengumpulan data melalui observasi, wawancara dan dokumentasi. Setelah data terkumpul dianalisis dengan model interaktif yaitu reduksi data, penyajian data dan menarik kesimpulan. Hasil dari penelitian ini menunjukan bahwa makam Badang keberadaan masih banyak yang berkunjung/berziarah bukan hanya masyarakat Pulau Buru dan wilayah Tanjung Balai Karimun tetapi wisatawan luar negeri seperti Singapura, Malaysia berziarah ke makam Badang dan juga masyarakat Pulau Buru menjadikan Makam Badang ini sebagai makam keramat. Pada tahun 2010 makam Badang dijadikan cagar budaya oleh Dinas Pariwisata Tanjung Balai Karimun.
\end{abstract}

Kata kunci: Eksistensi, makam Badang, Pulau Buru

\begin{abstract}
This research sees the existence of Badang tomb as a Religious tour in Buru Island Tanjung Balai Karimun at this time. Islanders rush to believe in the Badang tomb as a place to grant reguests. The purpose of this research is to existence of grave of grave Badang. This type of research is qualitative with descriptive. This research was conducted in Buru island, the source of data in this study there are two primary sources like community leaders, sub-district data and secondary sources such as visitors, literature. After collected data is analyzed with interactive model that is data reduction, data presentation and draw conclusion. The results of this study show that rhe grave of Badang existence is still a lot visiting/pilgrimage not only the community of Buru island and Tanjung Balai Karimun region but foreign toursts such as Sinagpore, Malaysia pilgrimage to the grave of Badang and also the community of Buru Island make this tomb Badang as a sacred tomb. In 2010 Badang grave used as a cultural heritage by the tourism office Tanjung Balai Karimun.
\end{abstract}

Keyword: Existence, Badang grave, Buru Island 


\section{PENDAHULUAN}

Karimun merupakan daerah tujuan wisata dari negara-negara lain. Jumlah turis yang cukup besar ini memberi peluang pada Kabupaten Tanjung Balai Karimun untuk di kembangkan objek-objek wisata serta fasilitas lainya. Pada tahun 2008, wisatawan asing yang berkunjung ke Karimun sebanyak 229.460 orang. Wisatawan asal negara Singapore dan Malaysia yang paling banyak mengunjungi Karimun (Gunawan, 2007 : 73).

Pulau Buru, adalah kecamatan yang ada di Kabupaten Tanjung Balai Karimun, terdapat 2 Kelurahan dan 2 Desa Kecamatan. Kecamatan Buru merupakan salah satu kecamatan terdiri dari berbagai ragam suku bangsa diantaranya adalah suku Melayu, Tionghoa, Jawa, dan Batak, terdapat berbagai macam juga wisata di Pulau Buru, salah satu wisata yang cukup menarik di Pulau Buru adalah wisata religinya seperti makam raja-raja terdahulu dan makam Badang (hulu balang Kerajaan Lingga). Di Pulau Buru sebagian besar masyarakat beragama Islam, namun sebagian mereka masih ada yang percaya animisme dan dinamisme, salah satu yaitu percaya terhadap makam Badang sebagai tempat untuk meminta suatu keinginan atau tempat terkabulnya doa.

Makam Badang ini adalah tempat peristirahat terakhir hulu balang kerajaan Lingga yang bernama Badang yang memiliki kekuatan yang sangat sakti yaitu kebal akan bendabenda tajam tidak ada yang bisa menandingi kekuatan dari Badang ini. Ukuran makam Badang ini adalah 30x30 meter. untuk pergi ke makam Badang ini cukup jauh karna letak makam Badang ini ditengah-tengah hutan Pulau Buru, tidak hanya berziarah ke makam ini nanti di makam akan ditemukan tongkat kayu yang panjang menurut pendapat masyarakat bisa mengukur umur seseorang jika diukur dengan rentangan tangan.

Berdasarkan dari latar belakang diatas penulis akan mengangkat tentang eksistensi makam Badang sebagai wisata religi di Pulau Buru karena wisata ini memiliki banyak nilainilai sejarah dari Badang menjadi hulu balang Kerajaan Lingga lalu sibadang meninggal dan dikebumikan di tempat Badang berasal yaitu Pulau Buru yang tertelak di Tanjung Balai Karimun, ukuran kuburan yang panjang, menjadi daya tarik tersendiri bagi wisatawan. Berdasarkan latar belakang diatas, adapun batasan masalah dalam penelitian ini adalah a) Batasan Spasial penelitian ini adalah makam Badang sebagai Wisata Religi dan bertempat di Pulau Buru Tanjung Balai Karimun. b) Batasan Temporal dalam penelitian dilaksanakan pada Tahun 2018. Berdasarkan latar belakang dan batasan masalah diatas adapun rumusan 
masalah dalam penelitian ini adalah "bagaimana eksistensi makam Badang di Pulau Buru Tanjung Balai Karimun?’.

Adapun tujuan dari penelitian ini adalah menjelaskan eksistensi makam Badang di Pulau Buru Tanjung Balai Karimun. Hasil penelitian ini, diharapkan dapat digunakan dan bermanfaat bagi adalah a) Manfaat Teoritis: Penelitian ini diharapkan dapat menjadi sumber informasi dan referensi dalam dunia pendidikan Manfaat Praktis: Bagi masyarakat secara umum dapat mengetahui letak dan nilai-nilai adat pada generasi muda, sejarah dari makam Badang di Pulau Buru Tanjung Balai Karimun.

\section{METODOLOGI}

Jenis penelitian ini adalah penelitian kualitatif dengan metode deskriptif Dalam buku metode penelitian ilmu sosial, menjelaskan bahwa penelitian kualitatif adalah meneliti informan-sebagai subjek penelitian dalam lingkungan hidup keseharianya. Untuk itu, para peneliti kualitatif sedapat mungkin berinteraksi secara dekat dengan informan, secara apa adanya (wajar). Pemahaman akan simbol-simbol dan bahasa asli masyarakat menjadi salah satu kunci keberhasilan penelitian ini.

Penelitian memerlukan objek untuk memperoleh data yang mendukung dalam penelitian ini maka untuk mencapai tujuan penelitian dan tempat penelitian berkenaan dengan penyelusuran sumber data primer dan sekunder. data primer dilakasankan ditempat penelitian dilakukan di Pulau Buru Tanjung Balai Karimun dan data sekunder dilaksanakan di perpustakaan yaitu Perpustakaan Universitas Riau Kepulauan. Waktu penelitan dilakukan selama tiga bulan dari bulan Mei hingga Juli 2018, tidak menutup kemungkinan jika ada perubahan waktu dan kendala dalam penelitian ini.

Wawancara (interview) adalah cara-cara memperoleh data dengan berhadapan langsung, bercakap-cakap, baik antara individu dengan individu maupun individu dengan kelompok, wawancara melibatkan 2 komponen, pewawancara yaitu peneliti itu sendiri dan orang-orang yang diwawancarai. Teknik ini dilakukan untuk mendapatkan informasi dengan cara mengajukan pertanyaan kepada sumber primer atau pelaku utama, camat Pulau Buru, dan tokoh-tokoh masyarakat yang mengetahui tentang "Makam Badang". Teknik observasi yaitu teknik yang cara mengumpulkan datanya melalui pengamatan langsung ke tempat 
objek penelitian dan melakukan pencatatan terhadap suatu gejala peristiwa mengenai "Makam Badang".Teknik dokumentasi ini dipakai untuk mengetahui kebenaran atau bukti nyata dari penelitian seperti arsip, foto-toto, gambar.

Dalam penelitian ini adalah menggunakan metode penelitian deskritif, dengan langkah-langkah (Miles, 1992 : 17 - 19) : 1) Reduksi data diartikan sebagai proses pemilihan, pemusatan perhatian pada penyederhanaan, pengabstrakan, dan transformasi data "kasar" yang muncul dari catatan-catatan tertulis di lapangan. 2) Alur penting yang kedua dari kegiatan analisis adalah penyajian data, dan membatasi suatu "penyajian" sebagai sekumpulan informasi tersusun yang memberi kemungkinan adanya penarikan kesimpulan dan pengambilan tindakan. Penyajian dapat dipahami apa yang sedang terjadi dan apa yang harus dilakukan lebih jauh menganalisis, mengambil tindakan berdasarkan atas pemahaman yang dapat di penyajian-penyajian. 3) Kegiatan analisis ketiga yang penting adalah menarik kesimpulan da verifikasi. Dari permulaan pengumpulan data. Penganalisis kualitatif mulai mencari arti benda-benda mencatat keteraturan, pola-pola, penjelasan, konfigurasi yang mungkin, alur sebab-akibat, dan proposisi. Peneliti yang berkompeten akan menangani kesimpulan-kesimpulan itu dengan longgar, tetap terbuka dan skeptis.

\section{HASIL DAN PEMBAHASAN}

\section{A. Gambaran Umum Lokasi Penelitian}

\section{Letak Geografis}

a. Letak dan Luas Geografis

Secara geografis wilayah Kecamatan Buru terletak antara 103'24'15'’BT s/d

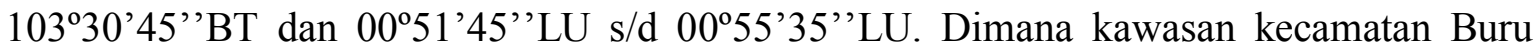
terdiri dari 2 (dua) buah pulau yang besar yaitu Pulau Gunung Papan dan Pulau Buru dengan luas area daratan 7.265 Ha dan luas perairan 1.135 Ha (Sumber data Kecamatan Buru).

Adapun batas-batas wilayah kecamatan Buru adalah sebagai berikut :

-Sebelah Utara : berbatasan dengan Kecamatan Karimun

-Sebelah Selatan : berbatasan dengan Kecamatan Belat

-Sebelah Barat : berbatasan dengan Kecamatan Belat

-Sebelah Timur : berbatasan dengan Kecamatan Moro

b. Topografi 
Kecamatan Buru merupakan kawasan dataran rendah yang terletak pada ketinggian 0-136 meter diatas permukaan laut. Dimana sebagian besar lahan merupakan lahan datar sampai bergelombang sedangkan lahan terjal hanya terdapat di Pulau Gunung Papan (Sumber Kecamatan Buru).

c. Iklim dan Hidro-oceanografi

Kabupaten Karimun secara umum beriklim tropis basah yang dipengaruhi oleh sifatsifat iklim laut, musim hujan berlangsung pada bulan Oktober, November sampai bulan April, dimana matahari berada dibelahann bumi Selatan dan angin bertiup Barat Laut. Musim kemarau berlangsung pada bulan Juni sampai Oktober, dimana Matahari berada pada belahan bagian utara dan angina bertiup dari arah Tenggara (Sumber Kecamatan Buru).

Curah hujan berkisar antara $2.000 \mathrm{~mm}$ sampai $2.054 \mathrm{~mm}$ setiap tahunnya dengan jumlah hari hujan kurang lebih 110 hari. Suhu rata-rata serendah $23,8^{\circ} \mathrm{C}$ dan tertinggi $33,2^{\circ} \mathrm{C}$, dengan kelembapan udara rata-rata $=85 \%$. Angin berhembus cukup nyaman, tidak terlalu besar karena terhalang berbagai pulau dihadapannya (bukan samudera lepas) arah angin bervariasi tergantung waktu. Pagi hari berhembus angina laut dan malam hari berhembus angina darat. Pantai di Pulau Karimun Besar pada umumnya landau kecuali di bagian utara disisi Barat, Selatan dan Timur (bagian Selatan) airnya relatif keruh dibandingkan dengan bagian utara tinggi air laut (pasang) berkisar anatara 1,0 meter sampai dengan 1,5 meter dengan kondisi gelombang tidak begitu tinggi.

\section{Kependudukan}

Jumlah penduduk Kecamatan Buru sampai akhir Desember 2018 berjumlah 10.400 jiwa, dengan perincian sebagai berikut :

Tabel 1. Jumlah Penduduk Kecamatan Buru

\begin{tabular}{|l|l|l|c|}
\hline \multirow{2}{*}{ No } & \multirow{2}{*}{ Jenis Kelamin } & \multicolumn{2}{|c|}{ Jumlah } \\
\cline { 3 - 4 } & & WNA & WNI \\
\hline 1 & Laki-laki & 5.168 jiwa & - \\
\hline 2 & Perempuan & 4.814 jiwa & - \\
\hline & Jumlah & 9.982 Jiwa & \\
\hline
\end{tabular}

Sumber data : Kecamatan Buru 
Tabel 2. Daftar Jumlah Keluarga Kelurahan/Desa se-Kecamatan Buru

\begin{tabular}{|l|l|c|}
\hline No & \multicolumn{1}{|c|}{ Kelurahan / Desa } & Jumlah \\
\hline 1 & Kelurahan Buru & 1.048 \\
\hline 2 & Kelurahan Lubuk Puding & 1.060 \\
\hline 3 & Desa Tanjung Hutan & 508 \\
\hline 4 & Desa Tanjung Batu Kecil & 553 \\
\hline & Jumlah & 3.169 \\
\hline
\end{tabular}

Sumber : Data base capil dan KB. Kab. Karimun Desember 2018

Adapun jumlah penduduk menurut kelompok umur (usia) dan jenis kelamin yang disusun perdesa atau kelurahan adalah sebagai berikut :

Tabel 3. Data Penduduk Menurut Kelompok Umur

\begin{tabular}{|l|l|l|l|l|}
\hline No & Umur & Laki-laki & Perempuan & Jumlah \\
\hline 1 & $0-4$ Tahun & 348 & 294 & 642 \\
\hline 2 & $5-9$ Tahun & 367 & 373 & 740 \\
\hline 3 & $10-14$ Tahun & 300 & 311 & 611 \\
\hline 4 & $15-19$ Tahun & 426 & 379 & 805 \\
\hline 5 & $20-24$ Tahun & 489 & 431 & 920 \\
\hline 6 & $25-29$ Tahun & 428 & 394 & 822 \\
\hline 7 & $30-34$ Tahun & 488 & 431 & 919 \\
\hline 8 & $35-39$ Tahun & 493 & 460 & 953 \\
\hline 9 & $40-44$ Tahun & 392 & 356 & 748 \\
\hline 10 & $45-49$ Tahun & 347 & 307 & 654 \\
\hline 11 & $50-54$ Tahun & 308 & 282 & 590 \\
\hline 12 & $55-59$ Tahun & 261 & 253 & 514 \\
\hline 13 & $60-64$ Tahun & 198 & 197 & 395 \\
\hline 14 & $65-69$ Tahun & 100 & 133 & 233 \\
\hline 15 & $70-74$ Tahun & 109 & 99 & 208 \\
\hline 16 & 75 tahun keatas & 114 & 114 & 228 \\
\hline & Jumlah & 5.168 & 4.814 & 9.982 \\
\hline
\end{tabular}

Sumber data : Kecamatan Buru 2018

\section{Ketenagakerjaan}

Tenaga kerja terlatih dan terdidik dalam berbagai sektor yang ada di Kecamatan Buru, seperti : Pegawai Negeri, Nelayan, Perdagang, Pertanian, Perikan, Jasa, Swasta

\section{Keadaan Sosial Ekonomi}

Di wilayah Kecamatan Buru sendiri terdiri atas penduduk dengan sumber penghasilan sebagai rumah tangga perdagangan, pertanian serta rumah tangga lainnya. Kecamatan Buru merupakan area yang srategis dan potensial sebagai wilayah 
pengembangan perekonomian dan industri. Masyarakat atau rumah tangga yang bekerja disektor pertanian meliputi perkebunan, pertanian tanaman pangan dan perikanan termasuk buruh termasuk buruh nelayan yaitu bekerja pada kapal penangkap ikan. Sesuai dengan statusnya bahwa desa-desa atau kelurahan di Kecamatan Buru adalah merupakan Desa/Kelurahan pantai maka sebagian mata pencaharian penduduknya adalah sebagai petani perkebunan, nelayan dan lain-lain.

Adapun komposisi prosentase mata pencaharian penduduk adalah:

\section{Tabel 4. Mata Pencaharian Masyarakat Kecamatan Buru}

\begin{tabular}{|l|l|c|c|}
\hline No & & Prosentase $(\%)$ & Keterangan \\
\hline 1. & Pertanian & 30,42 & \\
2. & Perkebunan & 4,68 & \\
3. & Perikanan & 49,09 & \\
4. & Wiraswasta & 12,02 & \\
5. & Kerajinan & 2,46 & \\
6. & Perdagangan & 0,09 & \\
7. & Pegawai Negeri/ABRI & 0,94 & \\
8. & Buruh dll & 0,30 & \\
\hline & Jumlah & 100 & \\
\hline
\end{tabular}

Sumber data : Kecamatan Buru 2018

\section{Potensi Pengembangan Wilayah Kecamatan Buru}

a. Pertanian Tanaman Pangan dan Perkebunan

Sesuai dengan penyebaran jenis tanah, keadaan iklim dan tata air, sebagian daerah Kecamatan Buru memiliki potensi untuk pengembangan pertanian tanaman pangan, perkebunan dan perternakan, yaitu : a) Perkebunan Sawit di Kelurahan Lubuk Puding, Desa Tanjung Hutan dan Desa Tanjung Batu Kecil. b) Pertanian Karet Unggul di Desa Tanjung Hutan, Kelurahan Buru, Lubuk Puding dan Desa Tanjung Batu Kecil. c) Perkebunaan Rakyat seperti kelapa dan sagu di Desa Tanjung Hutan, dan Kelurahan Lubuk Puding. d) Perternakan ayam buras, kambing, sapi di Desa Tanjung Hutan, Tanjung Batu Kecil dan Kelurahan Buru. e) Tambak ikan bandeng di Kelurahan Buru dan Desa Tanjung Hutan. f) Tambak udang di Desa Tanjung Batu Kecil dan Desa Tanjung Hutan.

b. Perikanan

Potensi ikan tergantung dipesisir sekitar Pulau di Kecamatan Buru memang tidak terlalu besar. Namun mengingat akan kebutuhan ikan di wilayah Kabupaten Karimun 
khusunya dan wilayah-wilayah berkembang lainnya disekitar Kepulauan ini, maka wilayah Kecamatan Buru menjadi potensial untuk pengembangan budidaya perikanan seperti keramba ikan, dan udang serta tambak ikan bandeng dan udang. Selain itu juga sektor kolam memungkinkan dikembangkan pada lahan-lahan yang dekat dengan pertanian/perkebunan.

c. Industri

Wilayah Kecamatan Buru potensi sekali untuk pengembangan industri pengolahan industri pengolahan hasil perkebunan/pertanian serta perikanan. Kecamatan Buru memiliki : 1) Industri kapal/sampan kayu di Kandis. 2) Industri arang di Desa Tanjung Batu kecil dan Desa Tanjung Hutan. 3) Industri batu bata di Kelurahan Lubuk Puding, Desa Tanjung Hutan dan Desa Tanjung Batu kecil. Letak geografis yang srategis merupakan faktor pendukung utama bagi pengembangan.

d. Pengembangan pariwisata

Kecamatan Buru memiliki objek wisata diberbagai tempat, antara lain yaitu

1. Objek wisata pantai Tanjung Ambat di Kelurahan Lubuk Puding.

Sebuah pantai yang terletak di Pulau Buru, menjadi objek wisata alami bagi masyarakat Pulau Buru waktu libur.

2. Objek wisata air panas di Desa Tanjung Hutan.

Pemandian air panas ini terletak di Desa Tanjung Hutan, konon airnya dapat diyakini sebagai obat. Banyak masyarakat sekitar Pulau Papan dan pulau-pulau sekitarnya yang datang mengunjungi bahkan wisatawan dari Malaysia dan Singapura.

3. Masjid tua Raja H.Abdul Ghani di Kelurahan Buru.

Inilah masjid tertua di Kabupaten Karimun. Dibangun oleh Raja Abdul Ghani bin Raja Idris bin Raja Haji Fisabililah, Seorang Amir pertama di Pulau Buru. Belum ada catatan pasti tahun berapa didirikan, namun yang pasti masjid ini dibangun pada pertengahan abad ke-19, yakni semasa kerajaan Riau-Lingga diperintahkan oleh Sultan Abdul Rahman Muazzamsyah (1883-1911). Karena dibangun oleh Raja Abdul Ghani maka masjid ini pun dinamakan masjid H.Abdul Ghani, namun belakangan, orangorang justru memanggil masjid ini adalah masjid Buru karena terletak di Pulau Buru.

4. Makam Badang di Kelurahan Buru.

Makam Badang diyakini sebagai tempat peristirahatan terakhir seorang hulu balang Kerajaan Lingga bernama Badang yang pada masanya dikenal gagah berani dan 
memiliki kesaktian tinggi, dari Pulau Buru, makam ini bisa mencapai setengah jam, menggunakan sepeda motor, kalau belum pernah kesana, sebaiknya mintalah penduduk setempat atau tukang ojek untuk menemani atau memberi petunjuk jalanya, sebab, meski jalur yang dilalui merupakan jalan beraspal, namun ketika sampai dijalan masuk lokasi makam, medanya cukup sulit sebab harus melintasi jalan setapak yang kanan kirinya dikepung pepohonan karet warga.

5. Makam Moyang Serage di Kelurahan Buru.

Makam ini terletak di Kampung Kandis, Pulau Buru ini adalah satu diantara situs makam di Kecamatan Buru yang berkatagori cagar budaya, seperti termuat dalam,"hikayat rakyat Kabupaten Karimun", makam ini dipercaya sebagai makam seorang nelayan bernama jumat, pendek ceritanya, dahulu kala hiduplah sepasang suami istri yang senantiasa hidup rukun, istri jumat hamil dan ingin memakan rusa putih, kemudian jumat mencari rusa yang dinginkan istrinya di Pulau yang diberi nama Pulau Buru ini, jumat bertekat, tidak akan pulang sebelum rusa tersebut ditemukan, lalu datang lah seorang raja yang ingin berburu dan menemukan binatang tapi seperti manusia yang bulunya lebat, lalu raja menyuruh pengawalnya mencukur bulunya, dikumpul bulunya hingga serage, dari situlah disebut makam moyang serage.

6. Kelenteng tua (Bo Sua Teng) di Kelurahan Buru.

Dulu, sebelum resmi bernama Cetiya Tri Dharma, viara ini merupakan klenteng bernama Bu Sua Teng. Kendati telah berganti sebutan namun nama Bu Sua Teng hingga kini masih terpampang jelas diatas pintu masuk bangunan utamanya. Pada masa awal pendirian, viara ini hanya memiliki satu ruang yakni bangunan $10 \mathrm{mx} 5 \mathrm{~m}$.

7. Gunung papan

Gunung papan yang terletak di Desa Tanjung Batu kecil, ini juga menjadi wisata alam bagi siswa pencinta alam yang ada di Kecamatan Buru karena pemandangan yang dilihat dari puncak gunung sangat indah, dari gunung ini juga dapat melihat Kota Karimun.

Di samping itu juga terdapat sejumlah kesenian yang semakin dibina dan dikembangkan untuk menunjang pariwisata yaitu :

a. Tari persembahan

b. Tari joget Mak Inang Dayang 
c. Hadrah

d. Berdah

e. Oerkes melayu

Sebagai pendukung pengembangan kepariwisataan saat ini sudah memadai antara lain :

a. Sarana transportasi ke Kecamatan Buru yang baik untuk Pulau Buru, Moro dan Pulau Batam yang sudah memadai.

b. Letak strategis.

c. Penyedian sarana air besrih.

\section{Sarana dan Prasarana}

\section{a. Sarana Ibadah}

Kehidupan umat beragama di Kecamatan Buru dapat dikatakan cukup mantap, dimana tercermin dalam kehidupan sehari-hari yang menunjukan persatuan dan keterpaduan antara pemeluk agama yang berbeda agamanya, belum pernah terjadi perselisihan paham tentang agama, hal ini tampak jelas dalam hal pembangunan dan pemeliharan bangunan-bangunan rumah ibadah, baik di ibu kecamatan maupun di desadesa dan keluruhan. Di Kecamatan Buru hingga saat ini telah berdiri hingga saat ini telah berdiri rumah ibadah

\section{Tabel 5. Jumlah Rumah Ibadah di Kecamatan Buru}

\begin{tabular}{|l|l|l|l|l|l|}
\hline No & \multicolumn{1}{|c|}{ Kelurahan/Desa } & Mesjid & Surau & Gereja & Vihara \\
\hline 1 & Keluruhan Buru & 3 & 2 & 1 & 2 \\
\hline 2 & Keluruhan Lubuk Puding & 3 & 4 & - & - \\
\hline 3 & Desa Tanjung Hutan & 4 & 1 & - & - \\
\hline 4 & Desa Tanjung Batu Kecil & 4 & 2 & 1 & 1 \\
\hline & Jumlah & 5 & 13 & 4 & 2 \\
\hline
\end{tabular}

Sumber data : Kecamatan Buru

\section{b. Organisasi Kepemudaan}

Adapun organisasi kepemudaan yang ada dan dibina oleh Pemerintah Kecamatan Buru adalah:

a. Kerukunan Pemuda Karimun (KPK) Ranting Kecamatan Buru.

b. Pramuka Ranting Kecamatan Buru dengan membawahi 12gugus depan,baik dari SD, SLTP, dan SMU yang berada di wilayah Kecamatan Buru.

c. Karang Taruna. 


\section{f. Profil Pulau Buru}

Pulau Buru berada di Kecamatan Buru dan merupakan bagian dari 247 pulau yang dimiliki Kabupaten Karimun. Letaknya, disisi tengah, diapit oleh Kecamatan Kundur Utara dan Kecamatan Karimun. Menurut cerita dari mulut kemulut masyarakat Pulau Buru, kalau Pulau Buru merupakan Pulau Sumpahan yang hanyut. Konon, sebelum menjelma menjadi sebuah Pulau Buru, Pulau Buru menyatu dengan daratan Johor, Malaysia. Adapun Pulau Buru mengapa dinamakan Pulau Buru, sebuah referensi menyebut, pulau ini dipanggil Pulau Buru karena dulunya merupakan tempat orang melakukan aktivitas berburu di hutan seperti banyaknya binatang yaitu pelanduk dan babi.

Pulau Buru telah menjadi destinasi wisata terdepan di Kabupaten Tanjung Balai Karimun. Terutama wisata religi di Pulau Buru, sejarah serta wisata alam, yang terkenal adalah Makam Badang, Masjid H Abdul Ghani, Vihara Cetiya Tri Dharma (Bu Sua Teng) serta makam Moyang Seraga, sementara untuk wisata alam, ada beberapa wisata alam, yang berparas bagus yaitu Pantai Ambat. Bisa juga mendatangi pemandian air panas atau natural hot spring water-nya yang berada di Tanjung hutan, Pulau Papan.

Akses menuju ke Pulau Buru juga terbilang sangat mudah. Ada tiga kapal regular dari Tanjung Balai Karimun yaitu menggunakan kapal Buru Indah, Karoma, serta Karimun. Ketiganya melayani rute Tanjung Balai Karimun - Pulau Buru atau sebaliknya dengan jadwal hampir satu jam sekali dimulai dari pukul 06.00 sampai dengan jam 14.00. yang berkisar sekitar 45 menit. Diluar roda transfortasi regular itu, anda juga bisa mencapai Pulau Buru dengan menyewa boat pancung adalah arternatif terbaik kalau bertolak rombongan atau grup. Sehingga punya waktu banyak untuk mengekplorisasi tempat-tempat menarik di Pulau Buru tanpa takut ketinggalan kapal.

Sementara aktifitas keliling Pulau Buru bisa mengunakan ojek yang bertarif tergantung jarak yang hendak di tempuh. Untuk menuju makam Badang misalnya, pulang pergi, para pengojek dengan harga Rp 15.000, sekali jalan. di luar ojek, cara hemat dan praktis menikmati pulau Buru adalah dengan berjalan kaki atau naik sepeda. Hanya memang, tidak ada penyewaan sepeda disana. Kalau sudah puas menapaki pulau Buru ini, jangan lupa membeli oleh-oleh khasnya yakni telur asin, kue bangkit atau kerupuk gelebe. Tetapi pangan tersebut tidak mudah didapat, harus memesan jauh jauh hari.

\section{g. Lokasi Makam Badang}


Makam Badang terletak di Kelurahan Buru, di Kecamatan Buru dari kota Buru bisa mencapai 30 menit atau setengah jam menggunakan sepeda motor, kalau belum pernah kesana sebaiknya minta lah arahan dari penduduk setempat atau ojek yang berada di kota Buru untuk menemani atau memberi petunjuk dilalui merupakan jalan beraspal, sksn tetapi ketika sampai dijalan masuk ke lokasi makam Badang, jalan yang dilalui cukup sulit dikarenakan melintasi jalan tanah dan jalan setapak yang kanan kirinya dikelilingi oleh pepohonan karet milik warga (Dinas Pariwisata Kabupaten Tanjung Balai Karimun)

Lokasi tepatnya makam si Badang ini jauh dari pemukiman warga, memasuki hutan karet, dari jalan raya berkisar tiga sampai empat kilo meter. Lokasinya makam Badang terletak di dikawasan lapangan berluas 30mx30m. Sekelilingnya terdapat berbagai macam pohon yang berukuran besar, diantaranya adalah pohon gaharu yang terlihat telah berumur puluhan tahun. Bagian depan makam ini terdapat sebuah gapura yang berfungsi sebagai pintu gerbang bertinggi empar meter lebih yang baru dibangun oleh pemerintah.Kabupaten Tanjung Balai Karimun yang bertuliskan "situs cagar budaya" gapura ini di cat berwarna kuning pada bangunan utamanya sementara di bagisan lis-nya berwarna hijau terang terlihat bersih dan rapi walaupun tidak ada yang membersihkannya (Dinas Pariwisata Tanjung Balai Karimun).

\section{Eksistensi Makam Badang Sebagai Wisata Religi di Pulau Buru 1. Sejarah Makam Badang}

Badang adalah seorang nelayan yang berasal dari Pulau Buru, setiap hari Badang memasang lukah untuk menangkap ikan, akan tetapi lukah yang dipasang selalu habis, seperti dimakan oleh binatang karena yang tersisa di lukah tersebut hanya tulang ikan. Suatu hari Badang melihat lukah yang dipasang di sungai Pulau Buru. Badang menemukan mahluk yang aneh yang menyerupai jin dengan bentuknya yang besar, tegap dan berbulu lebat. Kemudian memberanikan diri Badang menangkap mahluk tersebut, Setelah berhasil Badang menangkap mahluk itu, mahluk tersebut berteriak meminta dilepaskan oleh Badang. Badang akan melepaskan mahluk tersebut dengan satu syarat, agar mahluk tersebut memenuhi permintaannya.

Badang meminta kepada mahluk itu agar diberikan kekuatan yang tidak bisa dikalahkan oleh siapa pun, kemudian mahluk berkata "baik lah aku akan mengambulkan permintaan mu, aku akan muntah lalu kamu tampung muntah aku, dan kau makan muntah itu, seketika kau akan menjadi kuat". Setelah itu Badang mengambil daun untuk 
menampung muntah mahluk tersebut dan dimakan lah muntah mahluk itu, seketika Badang menjadi kuat dan bisa meruntuhkan pohon-pohon yang ada di sekelilingnya. Seketika mahluk yang tinggi tegap dan berbulu menghilang. Suatu hari ada sayembara untuk menjadi hulu balang kerajaan yang dikuti oleh Badang, Badang mengalahkan semua pendekar dari pelosok negeri. Badang akhirnya menjadi pemenang, yang kemudian diangkat oleh panglima kerajaan untuk menjadi pengawal. Saat itu Badang yang tinggal di Pulau Buru pindah ke istana kerajaan, nama Badang menjadi terkenal sebagai manusia kuat dari Pulau Buru. Ketika Badang wafat, oleh raja jasadnya dibawa kembali di Pulau Buru, dan dimakamkan, yakni di kawasan kelurahan Buru

Makam Badang diangap keramat oleh masyarakat Pulau Buru, karena masyarakat mengangap Badang orang bersejarah yang kuat dan menjadi hulubalang kerajaan Riau Lingga, akan tetapi makam Badang diangap keramat karena masyarakat Pulau Buru yakin jika mendatangi makam Badang dan melakukan permintaan atau bersumpah akan dikabulkan. Setelah dikabulkan orang tersebut akan datang kembali membawa semacam persembahan seperti beras ketan, ayam hitam dan telur. Tanda terima kasih dan rasa syukur mereka terhadap apa yang sudah dikabulkan. Dan ada beberapa kejadian yang diangap tidak lazim seperti hasil dari wawancara diatas yang membuat masyarakat tambah percaya akan dari kekeramatan makam Badang ini. Akan tetapi tetap semuanya serahkan kepada Allah SWT. Tidak ada yang tidak mungkin atas kehendaknya.

Dari hasil penelitian, dapat dijelaskan eksistensi makam Badang, dipengaruhi oleh kebudayaan turun-menurun dari nenek moyang dan menjadi tradisi yang dipercayai oleh masyarakat Pulau Buru dan masyarakat luar, hal ini sesuai dengan teori fungsionalisme yang dikemukan Durkheim (Jones, 2011 : 93) yang dikemukakan bahwa masyarakat terbentuk dengan struktur kebudayaan, yakni keyakinan dan praktek yang sudah mantap terhadap keyakinan dan praktek itu membuat masyarakat tunduk dan taat, seperti masyarakat Pulau Buru yang masih mempercayai keberadaan makam Badang dan menjadi tradisi serta kebiasaan di masyarakat sebagai tempat dikabulkan segala keinginan.

\section{KESIMPULAN DAN SARAN}

Berdasarkan pembahasan diatas oleh karena itu kesimpulan yang di peroleh adalah:. 
1. Pada tahun 1995 makam Badang dijadikan wisata religi di Pulau Buru. mulai dapat perhatian dari Pemerintahan Tanjung Balai Karimun dan Makam Badang dijadikan cagar budaya oleh Dinas Pariwisata Tanjung Balai Karimun. Pada tahun 2010 dan dikelola langsung oleh Dinas Pariwisata Tanjung Balai Karimun, makam Badang dijadikan salah satu ikon pariwisata Tanjung Balai Karimun

2. Makam Badang, sampai saat ini banyak yang mengunjungi makam Badang bukan hanya masyarakat Pulau Buru yang dijadikan tempat keramat atau tempat meminta akan tetapi makam Badang ini juga banyak menarik wisatawan asing luar dari masyarakat Tanjung balai Krimun seperti wisatawan negara Malaysia dan Singapore yang berkunjung kemakam Badang untuk berziarah dan menjadikan objek wisata makam Badang sebagai tujuan untuk libur

Berdasarkan hasil penelitian yang dilakukan oleh penulis setelah fakta dan makna sejarah di uraikan secara kronologis, menimbulkan suatu pertanyaan yang bersifat saran, diantaranya adalah:

1. Untuk mahasiswa agar benar-benar dapat mempelajari dan memahami hakekat sejarah serta mendalami konsep sejarah, dengan sejarah akan mampu menjadi pedoman pada masa akan datang.

2. Agar sejarah makam Badang bisa menjadi bahan muatan lokal dalam proses belajar mengajar di sekolah-sekolah dan dapat

3. Diharapkan bagi pemerintahan daerah Kecamatan Buru menjadi berkembang dan dapat menjadi situs sejarah sehingga daerah ini menjadi objek penelitian sejarah.

4. Meningkatkan sarana dan prasarana yang menunjang hinga wisatawan dalam maupun luar dapat merasa aman dan nyaman serta ada daya tarik perhatian untuk mengunjungi makam Badang.

\section{REFERENSI}

Gunawan Markus. (2002). Provinsi Kepulauan Riau. Batam: Titik Cahaya Eika.

Idrus Muhammad. (2009). Metode Penelitian Ilmu Sosial, Yogyakarta: Erlangga.

Ismawati Esti (2012) Ilmu Sosial dan Budaya Dasar. Yogyakarta, Ombak

Jones Pip, Dkk, (2016). Pengantar Ilmu Sosial (terjemahan Ahmad Fedyani Saifudin), Jakarta: yayasan pustaka obor Indonesia 
Kattsof Lois O, (2004) Pengantar Filsafat,(terjemah soejono soemargono) New York: The Ronald Press Company

Koentjaraningrat.(2009) Ilmu Antropologi, Jakarta PT Rineka Cipta

Martono Nanang.(2012) Sosiologi perubahan Sosial, Jakarta: Rineka Cipta

Mujib Misbahul.(2016). Tradisi Ziarah dalam masyarakat Jawa kontektasi kesalehan, identitas Keagamaan dan komersial, Yoyakarta: UIN Sunan Kalijaga. Ejurnal.IAIN Purwokerto.ac.id diunduh 9 Juli 2018

Mutis Thoby Dkk(2007) Keadaban Publik, Jakrta: Universitas Trisakti

Milles Matthew, dkk ( 1992) Analisisi data kualitatif, Jakarta: UI Press

Sammeng Mappi Andi.(2001) Ckrawala pariwisata, Jakarta:Balai pustaka 